\title{
Perwujudan Keyakinan akan Keberadaan Mahluk Halus dalam Komik Kawin ka Kunti
}

\author{
Kankan Kasmana, Setiawan Sabana, Iwan Gunawan, Hafiz Aziz Ahmad \\ Program Studi DKV-UNIKOM \\ Jl. Dipati Ukur No. 112 Bandung 40132
}

\begin{abstract}
Spiritual beings within Sundanese is both myth and reality phenomenon. This spiritualimmaterial belief influences Sundanese people's life, where it frequently appears in popular media. In 1986, there was a comic titled Kawin ka Kunti, told a story about spiritual being (Kuntianak)-human marriage.

It is a qualitative research which descriptively explains how myth and tradition are wrapped as an intertext form. Uses intertextual analysis, this research attempts to find text representation in form of belief on spiritual beings existence in the comic.

It is then concluded that intertext exists in the comic in form of belief on spiritual beings existence comprises of incarnation of several ghosts, spells presence in form of jampe pamakena, as well as custom related to ghosts. Ghost imaging in this comic is a representation of concept, point of view, and belief of ghost. It may come in form of perceptual imaging, presents in anything that is based on external reference of the comic artist her/himself.
\end{abstract}

Keywords: Ghost, Comic, Intertextual, Sunda, Tradition

\begin{abstract}
ABSTRAK
Mahluk halus dalam masyarakat Sunda merupakan fenomena antara mitos dan realitas. Kepercayaan terhadap mahluk yang dianggap immateri-spiritual ini mempengaruhi kehidupan masyarakat, dan banyak diangkat dalam media populer. Tahun 1986 hadir komik Sunda berjudul Kawin ka Kunti, bercerita tentang pernikahan manusia dan mahluk halus, Kuntianak.

Penelitian ini bersifat kualitatif, secara deskriptif menguraikan tentang pengemasan mitos dan tradisi dalam komik sebagai wujud interteks. Analisis intertekstualitas digunakan dalam penelitian berupaya mencari representasi teks berupa keyakinan akan keberadaan mahluk halus di masyarakat Sunda yang muncul dalam komik.

Diperoleh kesimpulan bahwa interteks hadir dalam komik berupa keyakinan akan keberadaan mahluk halus, meliputi wujud hantu, kehadiran mantra berupa jampe pamakena, serta adat istiadat yang berkaitan dengan mahluk halus. Imaji hantu dalam komik ini adalah representasi dari konsep, pandangan, kepercayaan akan kehadiran mahluk halus. Gambarannya bisa jadi merupakan sebuah imaji perseptual, yang hadir dalam diri komikus didasarkan pada referensi eksternal di lingkungan komikus berada.
\end{abstract}

Kata Kunci: mahluk halus, komik, intertekstual, sunda, tradisi 


\section{PENDAHULUAN}

Fenomena keberadaan mahluk halus di Indonesia sudah menjadi bagian kehidupan masyarakat, termasuk di Sunda, suku yang tinggal di Jawa Barat dan Banten. Sebagian masyarakatnya masih hidup dengan cara adat istiadat dan tradisi peninggalan leluhur. Berbagai aktivitas kehidupan dalam pelaksanaannya tidak lepas dari keyakinan akan keberadaan mahluk halus. Disebut demikian karena karakternya yang halus sehingga tidak dapat terlihat, dalam Islam disebut sebagai gaib; yang berarti tidak kelihatan atau tersembunyi. Selain Allah yang Maha gaib, dikenal pula mahluk halus lain seperti, malaikat, jin, setan (pengaruh Islam), dewa-dewi, karuhun atau arwah leluhur serta jurig. Jurig adalah terminologi bahasa Sunda yang khas disematkan pada hantu dengan beragam variasinya. Istilah jurig merupakan bentuk ujaran komunikasi dan ekspresi pengetahuan yang menunjukan kepercayaan masyarakat Sunda pada keberadaan mahluk yang absen secara fisik namun hadir dalam kepercayaan. 4 dari 5 orang Sunda saat ini, percaya bahwa mahluk ini hadir dan eksis di lingkungan sekitarnya. Sebelum Islam datang dengan ajaran iman pada mahluk gaib, keyakinan akan adanya mahluk halus sudah hadir sejak zaman Hindu-Budha. Dalam berbagai adat istiadat dan tradisi mulai dari tradisi orang melahirkan, khitanan, pernikahan, hingga orang meninggal, terdapat berbagai cara untuk menangkal/menghilangkan kesulitan atau keburukan dalam kehidupan sehari-hari, dianggap karena gangguan mahluk halus.

Hal ini mempengaruhi pandangan dan pola fikir masyarakat hingga kini, berdampak pada artefak, yakni hadirnya produk budaya yang mengetengahkan materi tersebut, termasuk salah satu produk budaya populer yakni komik. Tahun 1979-
1992 hadir komik strip Sunda, bertemakan keyakinan terhadap mahluk halus. Komik ini hadir dalam majalah Mangle serta surat kabar Giwangkara, keduanya media tersebut mengusung sastra dan budaya Sunda dalam kontennya. Komik yang hadir dalam Mangle di antaranya Supata, Mapay Tapak, Jurig Komersil, Ririwa nu Mawa Pati, Opat Madhab Setan, Guha Ririwa, Pucuk Kalumpang, Vorto ti Planet Vonzo, sementara dalam Giwangkara di antaranya: Kawin ka Kunti, Mata si Tumang, Harupat Kawung, Siluman Gunung Gantung, Munjung ka Buta, Getih, Ririwa nu Ngarah Pati, Cagak Kadal, Sasakala Ayana Aul, Karaton Rawa Buaya dan lain-lain. Komik tersebut hadir dengan beragam tema, mulai dari percintaan, balas dendam, permasalahan sosial-ekonomi, sasakala (asal mula kejadian), hingga rekayasa teknologi pada hantu dan manusia yang sudah meninggal. Disampaikan melalui cerita dengan genre horor, baik psikologis, slasher (pembunuhan), action (aksi-pertarungan) serta komedi.

Komik yang menjadi kajian dalam penelitian ini adalah komik Kawin ka Kunti, dibuat oleh komikus Duds. Menceritakan sekilas kehidupan (slice of story) seorang pemuda di Sunda yang menikahi mahluk halus-kuntianak. Komik ini sangat khas karena mengangkat tema yang dekat dengan kehidupan masyarakat tradisional Sunda, dengan cerita yang disertai adat istiadat dan tradisi yang berkaitan dengan mahluk halus. Menarik ketika salah satu unsur budaya tradisional ditangkap dan direpresentasikan dalam komik sebagai produk budaya populer. Budaya timur dikemas dalam sebuah produk yang berasal dari budaya barat.

Akan ditemukan intertekstualitas antara sastra lisan di masyarakat tradisional Sunda dengan komik sebagai sastra gambar, mencari teks berupa tradisi dalam budaya 
populer yang lebih modern sebagai upaya menemukan makna utuh komik sebagai sastra gambar. Penting kiranya dilakukan penelitian tentang hal tersebut mengingat penelitian jenis ini jarang dilakukan. Salah satu penelitian mengenai komik Sunda dengan tema hantu hadir tahun 2014 oleh penulis dan dimuat dalam journal Visual Art \& Design ITB, berjudul Ciri Visual Komik Strip Sunda Opat Madhab Setan dalam Majalah Manglé. Hasil penelitian menyebutkan adanya kekhasan dalam hal visual yang tidak dimiliki komik lainnya. Memiliki ciri visual berupa gaya gambar semi realis, dominasi gestur, tidak detail, inkonsistensi panel, tipografi manual menggunakan huruf besar, dominasi normal baloons, dominasi panel gabungan interdependen, onomatopea dalam bahasa Sunda. (Kasmana, Sihombing dan Irfansyah, 2014: 69-88). Kehadiran komik horor Sunda dengan tema budaya sangat sulit ditemui saat ini, hal ini menjadi urgensi lain, pentingnya penelitian ini dilaksanakan.

\section{METODE}

Penelitian ini adalah penelitian deskriptif kualitatif, akan ditemukan representasi gambaran mahluk halus kuntianak serta keyakinan terhadap mahluk halus, yang hadir dalam komik. Analisis intertekstualitas akan digunakan dalam penelitian untuk memahami komik sebagai sebuah karya sastra yang mengandung teks (tulisan dan gambar) sebagai sisipan dari teks-teks lain. (Rokhmansyah, 2014: 119). Teks yang dimaksud adalah sastra lisan yang hadir dalam kepercayaan masyarakat Sunda. Intertekstual juga dipahami sebagai proses untuk menghubungkan teks dari masa lampau dengan teks masa kini, tujuannya untuk memahami makna karya secara utuh. Sastra lisan adalah teks masa lampau, wujud dalam penelitian ini hadir dalam tradisi dan adat istiadat, sementara komik sebagai produk teks masa kini.

\section{HASIL DAN PEMBAHASAN}

1. Kepercayaan akan Mahluk Gaib di Masyarakat Tradisional Sunda dalam Tradisi dan Adat Istiadat

Dalam tradisi terkandung berbagai kebiasaan, aktivitas yang dilakukan oleh para orang tua, leluhur atau nenek moyang sebuah komunitas masyarakat dengan maksud dan tujuan menjaga manusia dari hal-hal yang tidak diinginkan. Di Sunda, saat ini masih terdapat beberapa tradisi yang dilakukan oleh sebagian masyarakat, disebut dengan talari yakni kebiasaan turun temurun dari orang tua dulu. Walau hidup dalam dunia modern, masih hadir semangat untuk mengangkat kembali tradisi sebagai ungkapan kebanggaan akan identitas dan jati diri sebagai suku Sunda. Ditandai dengan banyaknya kegiatan yang mengetengahkan tradisi dan kebudayaan, seperti berbagai pagelaran kesenian, penyelenggaraan upacara adat yang merayakan fase kehidupan seseorang mulai dari kehamilan, kelahiran, khitanan, pernikahan hingga kematian. Dilaksanakan bersinkretis dengan ajaran Islam, dikemas sedemikian rupa, disesuaikan dengan kondisi yang ada.

Terdapat hal yang khas dalam pelaksanaannya, beberapa tradisi baik sebelum ataupun sesudah mengenal Islam terdapat ikhwal yang berkaitan dan berhubungan dengan keyakinan pada keberadaan yang gaib. Surjaman (1962:.25) mengistilahkannnya sebagai mahluk halus, disebut demikian karena karakternya yang halus dan lembut, saking halusnya sehingga tidak dapat dilihat. Keyakinan tersebut terjadi di Sunda mengingat orang Sunda pada awalmya melihat alam sebagai satu kesatuan dari tiga dunia. Masyarakat Sunda 
pada awalnya memiliki pandangan tentang dunia, dalam naskah Sunda pada kropak 422, yang berisi tentang kosmologi Sunda Kuna (perpaduan Sunda-Hindu dan Budha) disebutkan bahwa alam raya ini terbagi menjadi tiga dunia, yakni sakala 'dunia nyata', yang dihuni oleh mahluk yang memiliki jasmani dan rohani, di antaranya manusia, tumbuhan dan benda lain yang dapat dilihat, bergerak dan diam. Kemudian Niskala 'dunia gaib', yang dipercaya dihuni oleh berbagai mahluk tak berjasad anasiranasir halus, berupa dewa-dewi, bidadarabidadari, apsara-apsari, ruh-ruh netral yang disebut sebagai syanu, bayu, sadap, dan hedap. Serta jantiniskala yakni dunia kegaiban sejati, yang dihuni oleh dzat yang Maha Tunggal disebut sebagai Sanghyang Manon. Dzat yang maha Pencipta disebut sebagai Si Ijunajati Nistemen, pencipta batas tapi tak terkena batas. (Darsa dan Ekadjati, 2006: 25). Dalam gambaran tersebut manusia Sunda awalnya percaya bahwa mereka tidak tinggal dengan jenisnya sendiri, terdapat mahluk lain (mahluk halus) yang biasanya disebut sebagai lelembut dan lelembutan. Menurut penuturan Didin (2015) lelembut adalah mahluk halus yang bukan berasal dari manusia artinya sudah ada sebelumnya, sedangkan lelembutan berasal dari arwah manusia yang sudah meninggal. Dalam sifatnya ada yang baik dan ada yang jahat, yang baik bersifat melindungi dan yang jahat bersifat menganggu. Pada kategori tempatnya ada yang tinggal di darat-tanah (hutan, gunung, gua, kuburan), langit, air (sungai, danau, sawah, kolam, rawa dan sumur), di pohon (beringin, kamboja, cempaka, kenanga dan lain-lain). Beberapa ada yang bersifat ngageugeuh (mendiami dan menguasai) suatu tempat dan sangat kultural artinya dipercayai sehingga muncul berbagai adat istiadat dan tradisi untuk menjauhkannya.
Melalui penelitian etnografi penulis tahun 2015-2016 (masih berjalan) terdapat ragam lelembut dan lelembutan yang diyakini oleh masyarakat Sunda (Jawa Barat dan Banten) saat ini. Data ini didapatkan melalui survei dan wawancara di berbagai daerah di Jawa Barat, serta bermacam literatur. Lelembut yang dianggap baik di antaranya: Guriang, Buta (kepercayaan urang Kanekes), Dangiang, Nyi Pohaci, Nini dan Aki Maranak, Dedewa, Nyi Rangga Manik. Sedangkan lelembut jahat di antaranya: Jurig Kuris, Jurig Teu Ngalahir, Jurig Tanpa Daksa, Jurig Kuluhu, Sungke Buana, Gajah Kuntianak, Jungjang Lawayan (ke 7 hantu ini dipercayai oleh masyarakat Kanekes hingga saat ini), Jurig Jarian, Genderuwo, Jurig Cai (tiga jenis di antaranya Titi Mangsa, Kala Mangsa dan Kili Mangsa), Sandekala, Kelongwewe, Kiciwis, Jurig Siit, Jurig Gonggo, Jurig Aden-aden, Lulun Samak, Jurig Balukang, Jurig Bulak, Jurig Conge, Jurig Kamangmang, Jurig Bagong, Kecit, Jurig Kancing, Buta Hejo, Jurig Monyet Bodas, Jurig Ipri, Jurig Aul, Kerod, Batara Kala, Siluman Gunung, Siluman Rawa, Dedemit, Rengkenek, Cabol, Loklok, Bungaok, Colek-colek, Banaspati, Jurig Kerud, Wiangga, Hantu Geni, Hantu Banyu, Tongtohot, Dongkol dan lainlain. Sementara itu lelembutan baik di antaranya Meong, Karuhun, Nyi Roro Kidul, Sang Hyang Kalang, Nini dan Aki Paranak. Sebaliknya lelembutan jahat diantaranya: Ririwa, Rabeg, Bobongkong, Kuntianak, Kuntilalakina, Centring Manik, Siluman Hileud, Baralak, Pajaratan dan Jurig Awi. Semua hantu tersebut memiliki kekhasan dalam hal karakter, sifat dan kelakuan. Terdapat di setiap daerah, dan ada cara untuk menjauhkannya.

\section{Komik Kawin ka Kunti}

Perkembangan komik Sunda bergantung pada keberadaan media 
berbahasa Sunda sebagai medium hadirnya komik tersebut. Tahun 80 -an hadir komik Sunda strip berseri dalam majalah Mangle dan Giwangkara, dengan berbagai tema yang menarik, mulai dari cerita yang diadopsi dari luar, keseharian, percintaan, legenda, masalah sosial dan bahkan cerita tentang hantu. Salah satunya berjudul komik Kawin ka Kunti (artinya menikah dengan Kunti). Komik yang terbit di majalah Giwangkara tahun 1986, bercerita tentang kehidupan seorang pemuda miskin bernama Udan yang berkelana mencari ilmu agama, pencarian ini merubah kehidupannya. Udan menjadi seorang ahli agama yang memiliki kemampuan melihat mahluk halus. Udan banyak menolong masyarakat yang diganggu oleh mahluk halus, termasuk menolong mahluk ini, salah satu di antaranya adalah kuntianak yang kemudian menjadi istrinya, Romlah. Romlah menjadi kuntianak karena ia meninggal saat melahirkan, arwahnya bergentayangan karena masih ada persoalan di dunia yang harus diselesaikannya. Udanlah yang menolongnya, dengan menusukkan jarum di kepala Romlah, sehingga Romlah berubah dari kuntianak menjadi seorang wanita cantik. Dalam perjalanannya mereka berdua menikah, dan akhirnya memiliki seorang anak Hadisah. Suatu ketika saat Hadisah mencari kutu di rambut ibunya, ia melihat ada benda berkilau di atas kepala sang ibu. Hadisah keheranan dan terus menerus mengingat benda itu sampai terbawa mimpi. Dalam mimpinya ia melihat kilauan di kepala bidadari, kemudian ia mencabut dan menjatuhkan jarumnya, di dunia nyata peristiwa itu adalah tercabutnya jarum yang

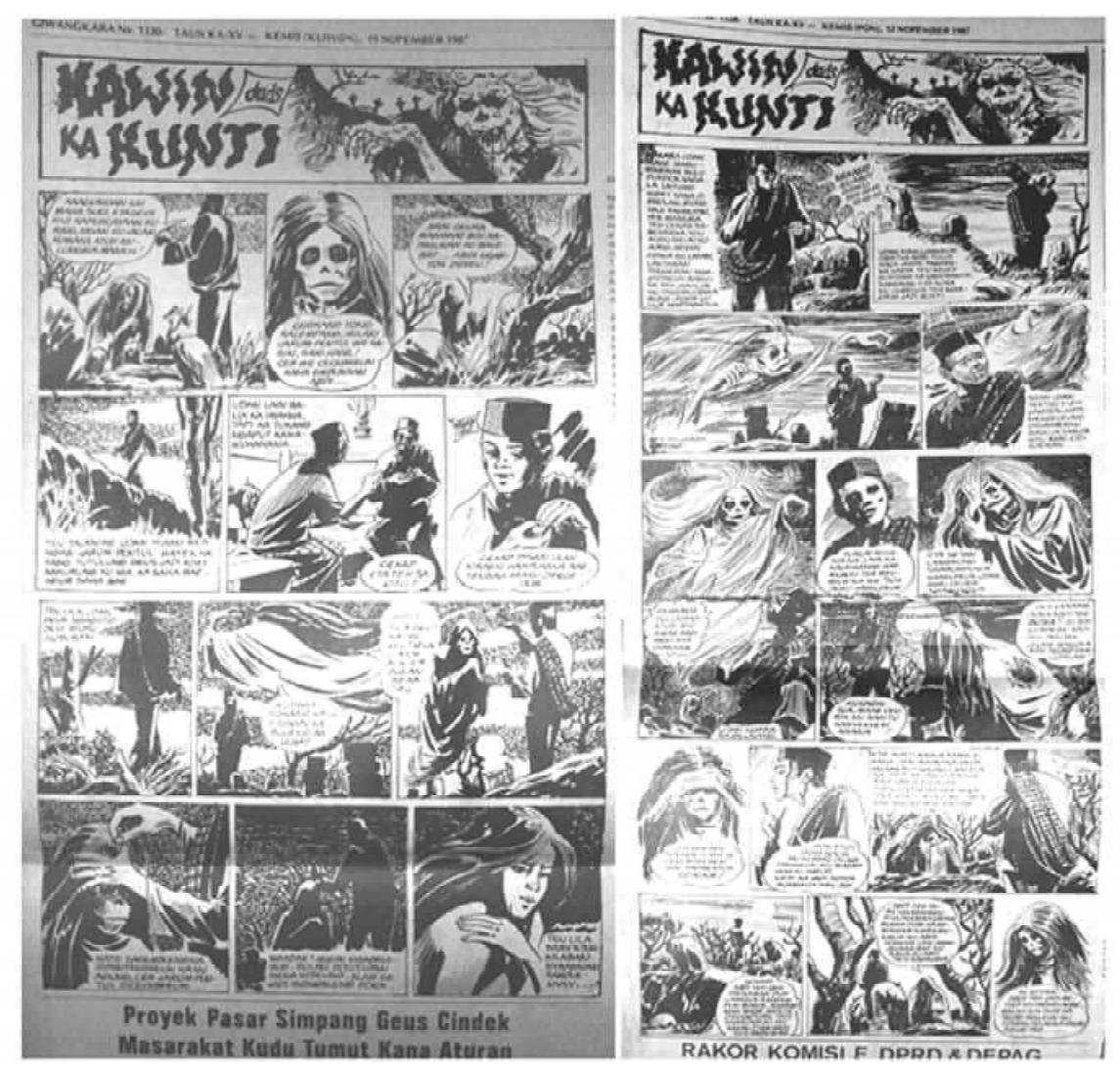

Gambar 1:

Cuplikan komik Kawin ka Kunti.

Sumber: Dokumentasi Giwangkara (2014) 
ada di kepala Romlah, dengan peristiwa tersebut kembalilah istri Udan ke wujud semula, kuntianak. Kesedihan menyelimuti keluarga termasuk Udan. Sampai satu ketika Udan bertemu Romlah. Udan kemudian memasukkan Quran ke lubang punggung si Kunti, dan berubahlah kuntianak menjadi seberkas cahaya yang melesat ke langit.

Komik ini dipilih karena memiliki tema yang sangat khas dekat dengan kehidupan dan kepercayaan yang ada di masyarakat Sunda. Selain itu dalam ceritanya menghadirkan romantisme kehidupan orang Sunda yang jarang ditemukan di komik Sunda lain.

\section{Analisis}

Karya yang diteliti adalah komik dengan judul Kawin ka Kunti, fenomena menarik dari komik ini adalah hadirnya hantu-hantu yang secara kultural dipercaya hadir di masyarakat Sunda. Kuntianak dalam adat istiadat Sunda disebut sebagai arwah gentayangan dari wanita yang meninggal ketika akan melahirkan atau ketika meninggal sedang mengandung bayi, namun karena salah dalam memperlakukan jenazah ketika dikubur atau akan dikubur. Cerita tentang fenomena Kuntianak ini hadir di sebagian besar masyarakat. Kepercayaan akan benarnya cerita ini masih ada di antara mitos dan realitas. Hadir turun temurun di masyarakat, sebagai sastra lisan, adat istiadatnya masih dipakai sebagian masyarakat. Berikut ini ikhwal tentang kehadiran Kuntianak dalam adat istiadat:

- Pada saat hamil usia kandungan 8 bulan, terdapat isyarat (daun-daunan dan bijibijian) di antaranya: panglay (Zingiber cassummanar), jaringao (Acorus calamus), daun salam (Syzygium polyanthum.), jukut palias (Pogonatherum crinitum thunb) yang disimpan di dalam kamar orang yang akan melahirkan. Dijaga juga dengan padika (ikhtiar optimal), palakiah (syarat untuk menolak bahaya), tarekah (mencari akal untuk keselamatan) serta kias (membantu orang yang melahirkan dan yang dilahirkan) supaya dijauhkan dari gangguan setan terutama kuntianak serta hantu lain yang ditakuti. (Mustapa, 2010: 24)

Jika saat hamil si ibu meninggal dan bayinya terbawa mati atau meninggal saat melahirkan, maka disebut-sebut meninggal karena gangguan kuntianak, maka cara menguburkan si ibu yakni pada kain kafannya di bagian tangan harus dijahit serta jarum yang digunakan untuk menjahit di kubur bersama si ibu. Hal ini dilakukan supaya si ibu tidak menjadi kuntianak. Kemudian di pojokpojok rumah keluarga yang meninggal disiapkan upih yakni pelepah daun pinang yang dirancang menjadi keris mainan, kemudian diberi motif belang dengan kapur seperti ular yang disatukan dengan daun nanas dan rumput palias agar dijauhkan dari gangguan kuntianak, terutama si ibu yang meninggal. (Soeganda, 1982: 43)

Menurut Soeganda (1982: 33) Kuntianak itu tinggal di hulu sungai, tempat orang mandi, di pohon-pohon tepi sungai, kemudian di daratan Kuntianak menyukai pohon yang harum bunganya seperti Cempaka, Pacar Cina, Kenanga atau pohon yang teduh dan yang dijalari tumbuhan lain atau akar yang menjalar yang dapat dipakai sebagai tempat berayun-ayun karena Kuntianak senang sekali bermain ayunan.

\section{a. Analisis Struktur Karya Transisi Analisis Intrinsik Tokoh dan penokohan}


Tabel 1. Penokohan

Sumber: Pribadi dengan gambar Komik Kawin ka Kunti, Giwangkara (1986)

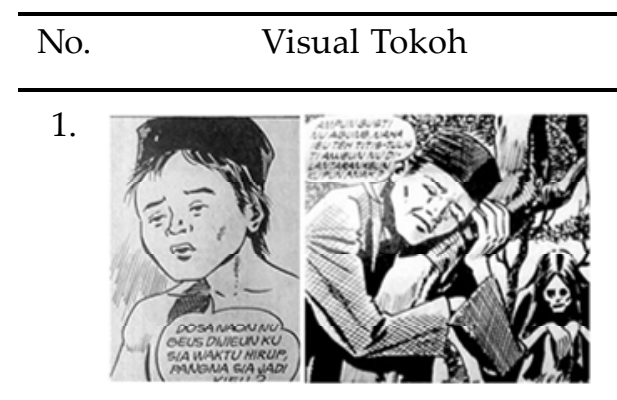

2.

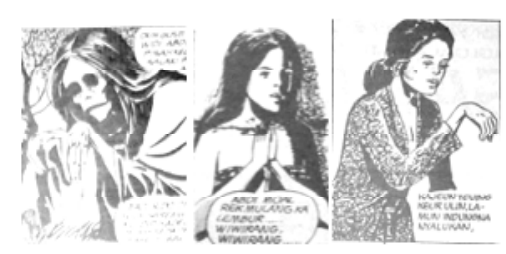

3.

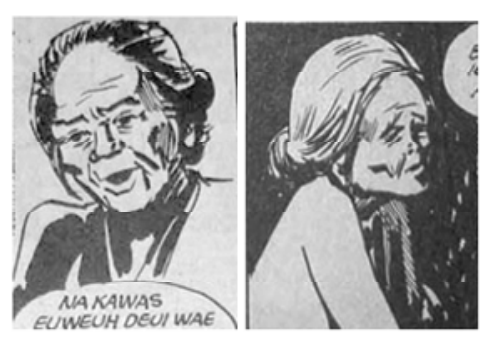

4.

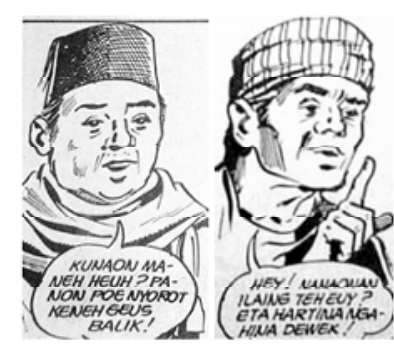

5.

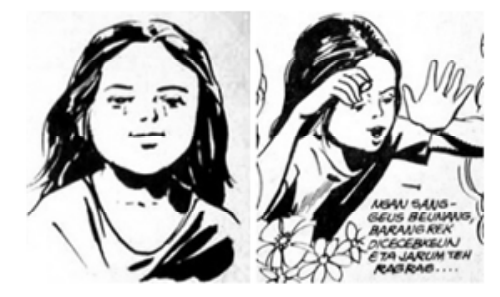

6.

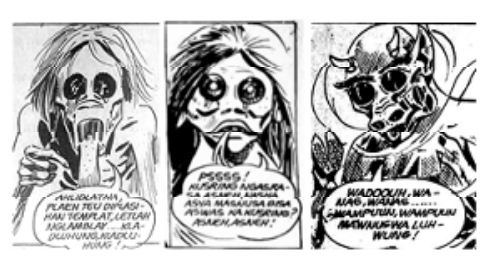

Deskripsi

Tokoh utama adalah Udan, seorang pemuda miskin yang giat bekerja mencari ilmu. Udan tokoh yang sangat sederhana, memiliki harapan menjadi orang besar suatu saat karena ilmunya. Udan seorang penolong, bukan saja banyak manusia ditolongnya, tetapi banyak juga mahluk halus yang ditolongnya. Karakter Udan adalah karakter yang rendah hati, pekerja keras, bijaksana dan sangat patuh pada ibunya.

Tokoh utama lainnya adalah Romlah (Oom), istri Udan yang wujud aslinya adalah Kuntianak. Romlah sangat cantik dan taat pada Udan. Romlah juga tokoh yang sangat hormat pada mertuanya. Pada saat dikaruniai anak ia sangat sayang pada anaknya, walaupun anaknyalah yang menjadikan Romlah kembali pada wujudnya semula. Digambarkan sebagai ibu-wanita Sunda dengan paras cantik.

Ema (Ibu Udan) tokoh pembantu dalam cerita ini. Seorang ibu yang sudah tua, ia sangat sayang pada Udan dan keluarganya. Ia adalah orang tua bijaksana yang menginginkan kebahagiaan bagi anaknya. Karakternya sangat khas memperlihatkan seorang wanita tua dari masyarakat tradisional Sunda, yang keibuan. Rengkuh dan rapuh, dengan kerutan di beberapa bagian wajahnya, menggambarkan sosok ibu yang berasal dari keluarga miskin.

Mama Ajengan, ia adalah seorang tokoh masyarakat, ustad yang dianggap memiliki ilmu tinggi tentang agama, memiliki pesantren tempat Udan mencari ilmu. Dikenal sebagai ustad yang kikir dan galak, namun saat ia disembuhkan sakitnya oleh Udan, ia sadar telah berprilaku buruk pada Udan. Berwajah gempal, dengan mengenakan sorban atau kopiah sebagai bentuk stereotip ustad di kampung.

Hadisah, anak Udan berumur 6 tahun. Ia sangat sehat, disukai oleh temannya dan memiliki rasa ingin tahu yang besar. Dalam mimpinya ia kehilangan jarum yang diberikan oleh bidadari, namun dalam kenyataannya ia mencabut jarum yang ada di kepala Romlah (ibunya) membuat Romlah kembali pada wujud semula (Kuntianak). Digambarkan sebagai sosok anak wanita yang cantik dengan wajar berbinar.

Tokoh pembantu lainnya adalah hantu-hantu yang berinteraksi dengan Udan yakni Jurig Ipri (hantu ular), Bobongkong, serta Jurig Tunggul (hantu yang mendiami sisa akar dan batang pohon yang sudah ditebang), mereka menjadi bagian dari kehidupan Udan yang memberikan pengalaman padanya berinteraksi dengan mahluk halus. 


\section{Plot}

Berdasarkan urutan waktu, maka cerita ini masuk ke dalam jenis plot kronologis (plot lurus-progresif), dan tidak ada flashback. Berdasar kriteria jumlah cerita yang terdapat dalam komik ini termasuk ke dalam plot tunggal, dengan hanya mengisahkan satu cerita saja, dengan cerita yang cukup padat.

\section{Tema}

Tema komik adalah tema non tradisional, yang dimaksud dalam hal ini tema yang diangkat merujuk pada ceritacerita yang melawan arus, mengangkat sesuatu yang tidak lazim, dan mungkin tidak sesuai dengan harapan pembaca. Dalam hal ini perkawinan antara dua mahluk beda dunia, serta dengan penyelesaian yang sedih (sad ending). Sementara tema berdasarkan pada tingkatan jiwa termasuk dalam tema tingkat tinggi (divine) yakni mengangkat masalah hubungan manusia dan sang Pencipta. (Stanton dan Kenny dalam Nurgiantoro, 1995: 67) melihat bahwa tokoh utama (Udan) mengembalikan segala sesuatu yang terjadi pada Allah dan membuatnya semakin dekat hubungannya dengan Allah.

\section{Latar}

Latar yang hadir dalam komik ini dibagi 3 yakni latar tempat, waktu dan sosial. Latar tempat didominasi oleh pedesaan, tidak disebutkan nama desanya, namun ditandai dengan hadirnya sawah, rumah panggung khas Sunda, tajug (masjid kecil), pesantren, sungai dan jembatan penyeberangan tardisional yang banyak ditemukan di desadesa di Jawa barat. Latar waktu terjadi dalam kurun lebih dari 15 tahun, dianggap bahwa waktu yang digunakan Udan menuntut ilmu hingga Udan memiliki serta berkelana ke berbagai pelosok desa hingga menikah dan mempunyai anak umur 6 tahun dilewati dalam kurun waktu 15 tahun. Latar sosial diperlihatkan bagaimana arketip kepemimpinan di masyarakat Sunda. Yakni hadirnya ajengan (ustad), sebagai tokoh masyarakat karena ilmu agamanya, begitu juga Udan yang menjadi tokoh masyarakat karena keahliannya menyembuhkan berbagai penyakit berkat bantuan akar beringin, ajimat pemberian dari jurig Bobongkong.

\section{Sudut Padang}

Sudut pandang yang dipilih adalah sudut persona ketiga 'dia', narator seseorang yang berada di luar tokoh menampilkan tokoh-tokoh cerita, menyebut nama atau kata gantinya: ia, dia, mereka. Narator mengganti ia, dia dengan menyebutkan nama dari tokoh-tokohnya seperti Udan, Romlah, Ajengan, dan lain-lain.

\section{Analisis Unsur Ekstrinsik}

Unsur ekstrinsik melihat aspek luaran komik seperti kehidupan komikus, pembaca, proses pembuatan dan teknis, termasuk dalam hal ini visual. Komikus adalah Duds namun belum ditemukan hingga saat ini siapakah Duds ini. Sementara itu mengamati penikmat komik ini adalah pembaca tabloid Giwangkara, merupakan khalayak dengan usia remaja hingga dewasa, di daerah Jawa Barat umumnya dan Bandung khususnya. Dengan pendidikan SD hingga perguruan tinggi. Pembaca adalah segmen khas yang menyukai berita dan hiburan yang disampaikan dalam bahasa Sunda. Menelaah hal teknis berkaitan dengan komik sebagai sastra gambar maka unsur ekstrinsik lainnya di antaranya gaya gambar, tipografi, balon kata, dan panel. Berikut penjelasannya:

\section{Gaya Gambar}

Gaya gambar yang dihadirkan dalam komik ini adalah gaya gambar semi realis, 
dengan format warna hitam di atas putih, teknik pewarnaan menggunakan tinta (drawing pen serta tinta China). Arsir yang tidak konsisten dan garis yang tegas merupakan ciri komikusnya. Garis pada panel terlihat tidak bersih dan tidak rapih.

\section{Tipografi}

Huruf yang digunakan dalam komik ini adalah tulisan komikus sendiri. Huruf tersebut muncul dalam teks judul, panel, balon kata, efek suara, dan nama komikus. Tulisan dalam komikus umumnya adalah format uppercase (huruf besar) dan miring (Italic), huruf besar biasanya digunakan agar tulisan jelas terbaca. Sementara huruf (tulisan Kawin ka Kunti) dibuat sedemikian rupa, dengan tipografi sebagai imaji, mengesankan horor dan menakutkan, di bentuk seperti gambaran onomatopea tubuh merinding. Tulisan tangan digunakan karena teknologi offset dan software saat itu masih sangat sederhana.

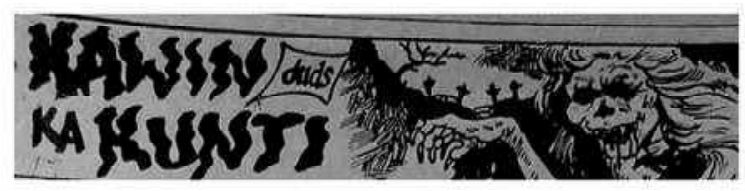

Gambar 2:

Tipografi pada judul (text as image) Sumber: Dokumentasi Giwangkara (1986)

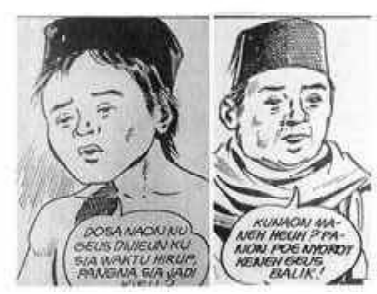

Gambar 3:

Tipografi pada teks, dengan format uppercase-italic

Sumber: Dokumentasi Giwangkara (1986)

\section{Balon Kata}

Dalam komik ini terdapat 3 jenis balon kata yang berbeda. Balon kata yang menunjukkan perkataan biasa, balon kata yang menunjukkan pikiran serta balon kata onomatopea (efek suara) dengan bentuk bulat lonjong dan kotak distorsi. Komik ini banyak didominasi oleh dialog yang langsung (pengutaraan secara langsung), melalui kata-kata. Serta banyaknya kotak balon kata yang berfungsi menjelaskan waktu atau sebuah keadaan. Dominasi balon kata tersebut menujukkan karakter orang Sunda yang senang berdialog/ mengobrol (ngawangkong). Berdasar pada filosofi hade goreng ku basa yang berarti baik atau buruk disampaikan melalui bahasa.

\section{Panel}

Dalam komik ini hanya terdapat panel yang menggambarkan keadaan yang sedang terjadi, serta panel yang menggambarkan keadaan waktu. Panel satu dan lainnya dihubungkan oleh beragam closure. Secara utuh komik ini menampilkan narasi yang menghadirkan tokoh-tokoh yang secara karakter dapat ditemui dalam kehidupan sehari-hari, termasuk dalam latar baik tempat waktu dan sosial. Kondisi di lapangan hal-hal yang berkaitan dengan mahluk halus ini masih dapat ditemukan dalam kehidupan masyarakat tradisional, dan bahkan dapat dijumpai di perkotaan.

\section{Analisis Hipogram dan Karya Transisi}

Hipogram dalam penelitian ini masuk dalam jenis hipogram aktual yakni teks nyata, teks yang menjadi latar penciptaan teks baru, baik tertulis atau teks lisan, termasuk juga adat-istiadat, dan kebudayaan (Pradopo 2003:132). Berikut analisis intertekstual yang ditemukan: 
Tabel 2: Analisis Hipogram

Sumber: Pribadi dengan gambar Komik Kawin ka Kunti, Giwangkara (1986)

\begin{tabular}{ccc}
\hline No. & Adat Istiadat dan Kepercayaan & Komik Kawin ka Kunti \\
Mahluk Gaib di Sunda & (Karya Transisi) \\
serta Sastra Lisan Sunda (Hipogram) &
\end{tabular}

1. Kuntianak wujudnya adalah wanita dengan rambut terurai menutupi punggungnya yang berlubang menurut kepercayaan di Sunda sangat takut dengan jala dan sirih. (Surjaman, 1962: 24)Kuntianak kata orang seperti orang perempuan, rambutnya terurai, punggungnya berlubang seperti lesung. (Soeganda, 1982: 33)"Kuntianak datangna biasana bau hanyir, awewe, rambutna panjang, jeung tonggongna bolong" artinya kehadiran kuntianak biasanya ditandai dengan bau amis, perempuan berambut panjang dan punggungnya berlubang. (Didin: 2015)

2. Kuntianak asalnya adalah wanita yang meninggal karena bayi yang dikandungnya sulit keluar dari rahim. (Danadibrata, 2009: 375.)

Sedangkan menurut Soeganda (1982: 33) asal Kuntianak itu dari orang mati waktu mengandung atau waktu bersalin, ruhnya akan menjadi kuntianak.

Menurut Didin (2015), "kunti teh awewe anu maot pas keur ngandung orok, dikuburkeun samanea" artinya Kunti itu wanita yang meninggal saat sedang mengandung bayi, dikuburkan asalasalan.

3. Menurut Mustapa (2010: 27) dalam adat istiadat mengurus perempuan yang meninggal waktu melahirkan atau sedang hamil maka kain jari-jari tangan perempuan itu harus dijahit, jarumnya harus ditusukkan ke kain tersebut dan dikubur bersama orang yang meninggal, agar tidak menjadi Kuntianak. Jarum menjadi benda yang dekat dengan keberadaan Kuntianak.

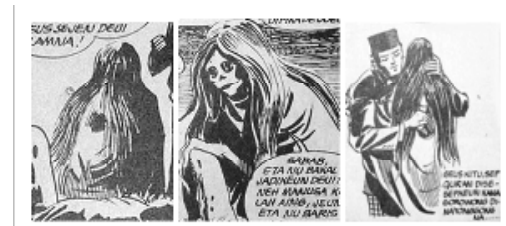

Tokoh Kuntianak, rambut terurai dengan punggung berlubang. Dalam potongan dialog gambar ke-3 disebutkan: "Geus kitu sep qur'an diseusepkeun kana gorowong dina tonggongna..." ("setelah itu dimasukan quran ke dalam lubang dipunggung-nya...").

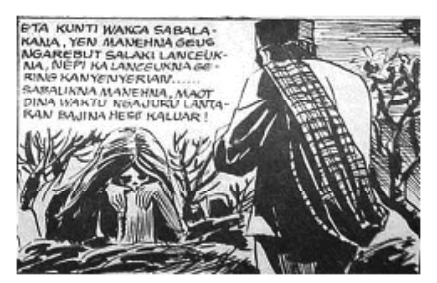

Terdapat dialog: "Sabalikna manehna, maot dina waktu ngajuru lantaran bajina hese kaluar!" (sebaliknya dirinya, meninggal pada saat melahirkan karena bayinya sulit keluar!)

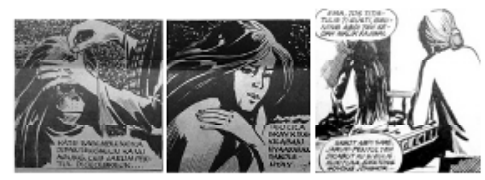

Dalam adegan ini diperlihatkan bahwa jarum (jarum pentul) yang ditusukkan ke kepala Romlah merubahnya menjadi manusia, begitu pula ketika dicabut merubahnya kembali menjadi Kuntianak. 


\begin{tabular}{ccc}
\hline No. & Adat Istiadat dan Kepercayaan & Komik Kawin ka Kunti \\
Mahluk Gaib di Sunda & (Karya Transisi) \\
serta Sastra Lisan Sunda (Hipogram) & \\
\hline
\end{tabular}

4. Kuntianak itu tinggal di hulu sungai, tempat orang mandi, di pohon-pohon tepi sungai, kemudian di daratan Kuntianak menyukai pohon yang harum bunganya seperti Cempaka, Pacar Cina, Kenanga, Kemboja atau pohon yang teduh dan yang dijalari tumbuhan lain atau akar yang menjalar yang dapat dipakai sebagai tempat berayun-ayun karena Kuntianak senang sekali bermain ayunan. (Soeganda, 1982: 34)

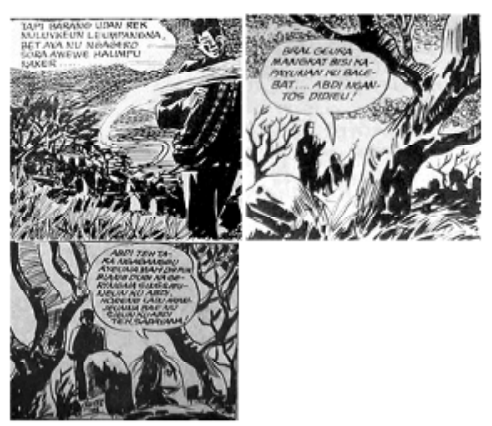

Melalui setting/latar tempat diperlihatkan Kuntianak ini tinggal di kuburan yang dipenuhi pohon-pohon besar, dan dari strukturnya terlihat pohon kamboja.

5 Terdapat mantera agar Kuntianak menjauh menurut Soeganda (1982: 33) sebagai berikut:

"Sangiang Sangandangan, Sangiang Sagendér Upih, ulah rék sinigawé ka urang manusia, manusia madia-pada, aing weruh ngaran sia, Nyi Godru, Nyi Buludru, Nyi Dangdang Saérang, Sang Suing Kaléandap, bekmati Sang Kunti-Anak, hurip ku Sang Anak-anak, Si Lunggupung ngaran indung, Ki Daleungdang ngaran bapa, anta maja anta guna, babu dayang sabrang kélong."

Dalam Etti RS, dkk. (2012: 190) terdapat jampi mengusir kuntianak "Bismillahirrahmaanirrahiim

Adegan Udan sedang mengeluarkan jimat dan

Sitéké putih sitaka putih sitoko putih aing nyaho siperbakat ratu sia nu sakeclak putih"

6 Orang yang mengandung dara (kehamilan yang masih muda) diberikan jimat oleh dukun beranak berupa ikat pinggang yang terbuat dari secarik kain berisi panglay (Zingiber cassummanar), rumput palias (Pogonatherum crinitum thunb), serta sedikit kemenyan. Kain yang digunakan adalah kain yang dibacakan hikayat Abdul Kadir Jaelani. Fungsinya menolak gangguan mahluk halus dan tolak bala (Soeganda, 1982: 20)

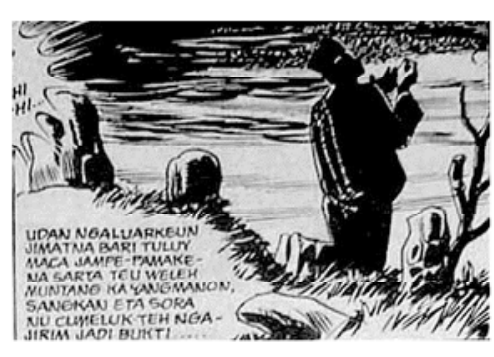

membaca jampi pamakena

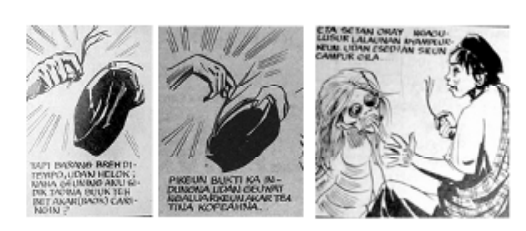

Gambaran jimat Udan yang awalnya adalah rambut jurig bobongkong dan berubah menjadi akar pohon beringin 
Hasil analisis memperlihatkan bahwasa Kuntianak yang hadir dalam dalam komik sebagai karya transisi, memiliki keterkaitan dengan adat istiadat kepercayaan di masyarakat Sunda yang diangkat dan direpresentasikan oleh ilustrator kedalam wujud komik melalui gambar dan tulisan. Komik menjadi karya transformasi yang di dalamnya terserap unsur-unsur hipogram. Komik ini juga menghadirkan visualisasi jurig (hantu) yang berasal dari sastra lisan, dan kepercayaan masyarakat Sunda. Mahluk halus sebagai mahluk yang immateri, invisible, absen, dan intangible, digambarkan oleh ilustrator berlatar belakang Sunda, dalam wujud yang bisa dilihat mata sebagi sebuah imaji-grafis (graphic). Dilatarbelakangi oleh pandangan orang Sunda sendiri terhadap mahluk halus, memungkinkan terjadinya ambiguitas pada pandangan dan pemahaman realitas, presentasi dan representasi. Imaji pada komik tersebut memungkinkan bukan hanya sekedar grafis, namun bisa jadi merupakan ide atau gagasan, persepsi atau bahkan sebuah simulasi.

Menurut Piliang, 2004: 129, presentasi adalah realitas yang dihadirkan di hadapan tanpa ada sebuah bentuk mediasi teknologis (Piliang 2004: 129), sebagian orang barat menganggap bahwa hantu bisa jadi realitas jika hadir melalui peralatan teknologi, berbeda dengan orang Sunda memandang mahluk halus bukan hanya sekedar konsep namun juga hadir (present) di sekeliling. Tidak perlu media teknologis apapun untuk meyakinkan bahwa ia hadir. Artinya seperti halnya jiwa-orang Sunda menganggap bahwasanya mahluk halus adalah sesuatu yang nyata, hadir secara immateri. Ia tidak absen dalam pandangan orang Sunda. Ia hadir dalam arti kata present. Walaupun kehadirannya tidak hadir secara fisik atau paraphysic. Oleh karena bagi orang Sunda mahluk halus dan kehadirannya merupakan bagian dari sebuah bentuk spiritualitas. Mahluk halus tidak dapat dilihat mata telanjang, ia bisa tertangkap dalam gambar atau bisa menunjukkan wujudnya pada situasi dan kondisi tertentu. Bagi mereka yang belum pernah berinteraksi, menganggap bahwa mahluk halus adalah sebuah kemungkinan, bisa ada, namun juga bisa meragukan. Menurut Piliang (2004: 57) realitas seperti halnya sebuah peta geografi yang dinamis, unsurunsurnya selalu berganti dan bertransformasi, realitas kini ditemukan dalam bentuk keterputusasaan (dicontinuity), keretakan (rupture) dan titik balik (reverse): ektrimitas, fatalitas, banalitas, dan promiskuitas: ketidakberaturan, ketidakterdugaan, ketidakpastian, dan keacakan, yang dalam kondisi tersebut banyak ditemukan persilangan, hibriditas, pesimpangsiuran, tabrakan tumpang tindih, pencampuran, hibriditas yang menciptakan realitas yang sangat kompleks. Melalui gambaran tersebut apakah mahluk halus Sunda termasuk ke dalam sebuah realitas, yang kini juga diperdebatkan definisinya bahwa realitas adalah sesuatu yang dapat ditangkap oleh indera (sense), atau hanya yang bersifat fisik (Piliang, 2004: 55). Jika mahluk halus adalah sebuah realitas maka imaji kuntianak yang ada dalam komik Sunda sebagai sebuah representasi dari konsep, pandangan, kepercayaan. Namun dalam gambarannya bisa jadi merupakan sebuah imaji perseptual, yang hadir dalam fikiran namun didasarkan pada sumber eksternal, karena bisa jadi bahwa apa yang digambarkan adalah hasil pengamatan, observasi dan wawancara, pengalaman dan bahkan hasil perjalanan spiritual yang dituangkan dalam bentuk ilustrasi. Namun memungkinkan pula bahwa gambaran tersebut adalah image mental yang hadir 
dalam diri ilustrator, karena kepercayaan yang dimilikinya.

Melalui komik ini digambarkan bahwasanya tradisi dan adat istiadat Sunda serta keyakinan dan ajaran agama Islam seakan-akan menjadi bagian yang tidak bisa dipisahkan. Adanya jampi, namun juga dipadu dengan doa dalam Islam, karakter tokoh yang mencirikan orang Sunda namun dengan keyakinan agama Islam yang kuat. Islam diterima sebagai keyakinan di masyarakat Sunda, namun juga orang Sunda sendiri tidak meninggalkan tradisi Sundanya itu sendiri, oleh sebab itu Sumardjo (2011: 23), mengatakan kosmologi Sunda zaman Islam masih menyertakan kosmologikosmologi sebelumnya. Dan begitu juga dengan kosmologi Islam Sunda tidak menghapuskan kosmologi sebelumnya, tetapi juga tidak meleburkan dalam konsep baru. Ia menambahkan bahwasanya semua konsep kosmologi tua yakni primordial Sunda dan Hindu tetap dipertahankan hanya disusun secara terpisah. Dalam hal ini dapat dianggap bahwa Islam bersinkretis dengan budaya setempat. Membaca komik jenis ini memberikan pengalaman yang khas bagi orang Sunda, memberikan semacam romantisme serta kerinduan pada hal-hal yang berkaitan dengan Sunda dan kesundaan.

\section{SIMPULAN}

Kesimpulan dari penelitian komik Kawin ka Kunti ini adalah:

1. Komik Kawin Ka Kunti menghadirkan wujud/visualisasi Kuntianak dengan referensi mengacu pada kepercayaan dan adat istiadat Sunda.

2. Terdapat perbedaan konsep atau pandangan terhadap realitas di dunia barat dan timur, dalam hal ini pandangan realitas di Sunda, yang tidak harus berwujud.
3. Islam sebagai sebuah keyakinan menyatu dengan adat istiadat serta tradisi setempat berakulturasi dan tanpa friksi di masyarakat Sunda

4. Adat istiadat dan tradisi adalah sebuah tema yang menarik untuk diangkat ke dalam bentuk produk budaya populer.

Keberadaan komik jenis ini sudah sulit ditemukan, hal ini menjadi signifikansi untuk penelitian-penelitian lanjutan. Masih terdapat aspek-aspek lain dalam komik yang dapat diteliti dengan berbagai sudut pandang keilmuan. Bagi penulis penelitian ini merupakan awal dikembangkannya penelitian lain terkait komik Sunda, mengingat penelitian senada masih jarang dilakukan.

\section{Daftar Pustaka}

Alvian Rokhmansyah

2014 Studi dan Pengkajian Sastra: Perkenalan Awal Terhadap Ilmu Sastra. Yogyakarta: Graha Ilmu.

Burhan Nurgiantoro

1995 Teori Pengkajian Fiksi. Yogyakarta: Gadjah Mada University Press.

Etti R.S., Dkk.

2012 Jangjawokan, Inventarisasi Puisi Mantera Sunda. Bandung: DISPARBUD JABAR.

Jakob Sumardjo

2011 Sunda Pola Rasionalitas Budaya. Bandung: Kelir.

Kankan Kasmana, Riama Maslan Sihombing, Irfansyah

2014 Ciri Visual Komik Strip Sunda Opat Madhab Setan dalam Majalah Manglé, Journal Visual Art \& Design ITB Vol. 6, No. 2

Penghulu Haji Hasan Mustapa

2010 Adat Istiadat Sunda. Bandung: Alumni. 
R.A.P. Soeganda

1982 Adat Istiadat Sunda. Bandung: Penerbit Sumur Bandung.

R.A. Danadibrata

2009 Kamus Basa Sunda. Bandung: Kiblat Buku Utama \&Universitas Padjajaran.

Rachmat Djoko Pradopo

2003 Beberapa Teori Sastra, Metode Kritik, dan Penerapannya. Yogyakarta: Pustaka Pelajar.

Ukun Surjaman

1962 Kepertjajaan Orang Sunda terhadap "Machluk Halus". Depok: FSUI, Universitas Indonesia.
Undang A. Darsa, dan Edi S. Ekadjati

2006 Gambaran Kosmologi Sunda. Bandung: Kiblat Buku Utama.

Yasraf Amir Piliang

2004 Posrealitas: Realitas Kebudayaan dalam Era Postmetafisika. Yogyakarta: Jalasutra.

\section{Wawancara}

Didin, Wawancara tentang Mahluk Halus, 20 September 2015 Bojongkoneng Cibeureum

Alm. Haryadi Suadi, Wawancara tentang komik Sunda, Februari 2015, Cisangkuy 